\title{
Role of Projects in the Study of Mathematics
}

\author{
Elena Sergeeva \\ Nosov Magnitogorsk State Technical University, Department of mathematics,455000 Magnitogorsk, Russia
}

\begin{abstract}
Today, it is difficult to imagine the education of children at schools and universities without the use of a project-based approach. Pupils and students carry out projects in all subjects on a variety of topics. Mathematics is one of the most difficult subject at schools. Mathematics is the most abstract subject out of all studied at school, and this is one of the reasons for difficulties the students face. This may be solved by introducing projects showing the applied value of mathematics, its relationship to other subjects, and to life in general. Projects help students to better understand the topic, to demonstrate their creativity. While implementing the project tasks students develop their cognitive skills, ability to independently navigate in the information space, ability to independently produce and design knowledge and many others. Students also carried out crossdisciplinary projects, which clearly demonstrated the relation of mathematics to everyday life and to other subjects. Then, scientific and practical conference was held based on the results of the projects.
\end{abstract}

At present, education at schools and universities is rather complicated without the project-based approach. Students at schools and universities carry out projects almost in all subjects and in a variety of topics. For the first time children get acquainted with the concept of a project already in the first grade. And their parents, people of the previous generation, studied at school, many of them graduated from higher education institutions, and never dealt with projects. Do pupils really need project activity these days?

Mathematics is one of the most difficult subjects at school. The reasons for this date back to over a three thousand-year history of mathematics. Mathematics is the most abstract subject out of all studied at school, which makes it difficult for pupils to study since it is based on objects and concepts, which do not exist in nature. Every mathematical concept is merely a model, an image of a real object. Another reason of difficulties to study mathematics is a relatively large volume of knowledge within a subject. For example, the study of a new material in the Russian Language ends in the $9^{\text {th }}$ grade, and in the high school students only repeat and master the acquired knowledge. In case with mathematics, school students study complicated new material until the end of the $11^{\text {th }}$ grade, and they also need to prepare for the exams in parallel! After leaving the school, for instance provided a student enters a technical university, he still faces difficulties in studying mathematics. Higher mathematics at a technical university is generally taught during the first and second years of study, and the majority of students face a lot of difficulties. First of all, this is again caused by the abstract nature of mathematics. Secondly, in recent years there has been a huge reduction of classroom hours, and the volume of material in a subject remained the same. Now students shall study a huge bulk of material independently. Hence, the course of mathematics includes too many concepts, ideas and methods. Many students are not able to master them for the time allocated. This may be solved by introducing projects showing the applied value of mathematics, its relationship to other subjects, and to life in general. Projects help students to better understand the subject, to demonstrate their creativity. As a result, they do not anymore perceive mathematics as an abstract and ideological science. And what is a project?

To answer this question, let us first understand the notion of a "project" together with the history behind the project-based approach.

The project-based approach appeared at the beginning of the $19^{\text {th }}$ century in America. It followed the problem-based approach developed by J. Dewey (an American philosopher and a teacher). The basic principle of this scientific school implies that the education of a child is based on the postulate "everything comes from life and for life". The personal interest of a child is on the first place, that is why children study well.

The attempts to introduce the project-based approach in Russia appeared almost alongside with the same approach developed by American teachers and philosophers. In 1920 s of the $20^{\text {th }}$ century the projectbased approach was supported in Russia by B.V. Ignatyev, M.V. Krupenina, V.N. Shulgin. Their motto is transformation of "a school of study into a school of life". As a result, pupils acquired knowledge during their performance, and educational projects represented socially useful matters of teenagers and children. Too active application of the project-based approach had an

Corresponding author: sew1108@yandex.ru 
adverse effect on students' knowledge in various subjects. Students worked in factories, plants, collective farms, school workshops, etc. and acquired only the knowledge related to practical work. Hence, the level of general education sharply decreased, and the schools had to refuse from the project-based approach [1].

During many years the project-based approach was not relevant. At present, the project-based approach in education is revived, but some of its aspects are reconsidered. One of developers of this approach in modern Russia is E.S. Polat. Nowadays, the projectbased approach is rather popular due to demands of the society. Today, employees need competent experts understanding all peculiarities of work, independent, initiative, able to develop a global mindset and to defend their position. All these is taught during project creation and defense.

According to I.D. Chechel, who worked with research projects, the project is literally defined as a "thrown ahead", i.e. a prototype of any object or kind of activity. According to him, the project is aimed to activate cognitive activity and to develop creative thinking [6]. When students work on a group project they learn to work in a team, take responsibility for their decisions, and analyze outcomes of their activity. If to consider the concept of a "project" in pedagogics, it represents a certain image, an idea, a plan. It may be presented as tables, calculations, drawings, descriptions, books, albums, presentations, booklets, etc. According to N.A. Kral, a project is considered within two notions: 1) as a result of project activity and 2) as a form of organization of joint activity of people [2, pp. 13].

The authors consider the project as a creative work of students performed on a specified topic independently only with the assistance of a teacher; and as a form of organization of joint activity of students [6].

Therefore, in this study the project-based approach means the process of development of a certain topic and its presentation as a project in some externally expressed form - graphic representation, multimedia presentation, in the form of an album, a booklet, finished layout, etc. [7].

Among the main requirements to projects there are the following: 1) material of a project shall correspond to interests and opportunities of students; 2) research (creative) task shall be relevant; 3 ) free choice of project layout and structure, methods of achieving the objective, references; 4) presence of practical, theoretical or informative importance of the considered project; 5) application of research methods in the project [7].

The project-based approach always fosters the motivation of students who see personal meaning of their education.

According to L.B. Pereverzev, the project-based approach includes three stages: 1) appearance of the hypothesis; 2) transformation of the initial idea into gradually complicated project; 3 ) execution and defense of a project. [5]. V.I. Slobodchikov considers seven stages of the project-based approach. The analysis of various works resulted to four main stages of the projectbased approach: 1) organization (identification of a problem followed by further study, hypothesizing); 2) activity (direct development of a project); 3) reflexing (comparison of planned and actual results, adjustment of results); 4) final (generalization, conclusions, documentation) [6]. When creating projects in mathematics there is a need to use knowledge from various fields of art, routine life, science and technology. During project implementation a pupil or a student tests his new social role, gains independently the missing knowledge, raises questions and looks for the answers, defines methods and means to achieve the objective.

At the same time, a teacher sets the task and then acts as a consultant. The authors share the opinion of E.S. Polat that the project-based approach covers a wide range of problem, research, and study methods, which help to gain a certain result - to find a solution to a specified problem. Besides, due to these methods the project is developed completely through the use of crossdisciplinary relations, consideration of various cases and conditions of its solution and analysis of the obtained results [3].

The application of projects in education contributes to the development of students' competences in the field of independent cognitive activity, including the development of mathematical competence in the course of mathematical training due to the fact that students develop their cognitive skills, ability to work independently in the information space, ability to independently acquire and structure their knowledge, etc. Besides, projects develop students' critical thinking, without which the implementation of mathematical competence in professional activity of future technical experts, is impossible.

In the past, a tutorial workshop covering theoretical fundamentals of a project-based approach, finished projects in different subjects, their advantages and disadvantages was held at the beginning of a course in mathematics at a technical university and prior to the fulfillment of the first project. Currently, when schools actively apply project-based approach, there is no need for such workshops, children perfectly know what is the project and how to deal with it. It is sufficient enough to describe the main aspects of a future project. Students are given at least three weeks to prepare a project.

Let us consider some topics of students' projects in mathematics at a technical university. First, students prepare projects within the studied topics, for example: Matrixes, Vectors, Derived Function and present an individual or a group project (depending on the topic, level of knowledge in mathematics).

Let us also consider the examples of students' projects related to the solution of professional tasks where mathematics plays the applied role. When studying the Quadric Curves and Space Bodies, students were offered a project in the "Unusual figures in our world". Students made prototypes of figures, geometric bodies, prepared multimedia presentations and reviews. The most successful projects ("Impossible figures", "Penrose Triangle", "Impossible Reutersvard's triangle", "Moebius band") were creative and performed with a lot of imagination.

Students also carried out cross-disciplinary projects, which demonstrated the relation of mathematics to 
everyday life and to other subjects. Within crossdisciplinary projects mathematics relates to other twothree subjects, for example, physics, or disciplines within the academic profile. For example, future architects prepared projects in "Mathematics in building and architecture". They designed models of various buildings with such presentations as the "World of Architecture and Mathematics", "Geometry in Construction", "Building Structures", "Favorite Architecture of the Hometown", "Anthropometry in Design of Buildings". Students show a lot of interest in projects demonstrating the relation of mathematics to routine life. For example, students studying mathematical statistics worked on such group projects as "What is the Relation between Sports and Mathematics?". "Life and Mathematics" was of a particular interest among students. Various projects were developed: "Mathematics in art", "Unusual phenomena in gold section", "Laws of the nature and laws of mathematics", "Bee honeycombs", "To draw is to deceive", "Fantasy world of fractals", "Problems of space debris", "Mathematics in ancient times", etc.

Upon this, the scientific and practical conference, where students defended their projects, was held. In the course of project development students were able to find the application of mathematics in tennis, soccer, volleyball, and chess. Students studying Economics had very interesting projects on "Mathematics in Economy". Other students presented projects on the creation of a personal house, summer cottage, summer cafe, etc.

The defense of projects at workshops and scientific and practical conferences contributes to the development of communicative and reflexive abilities of students since they are engaged in a debating dialogue with their fellows thus protecting and defending the project and analyzing the results of their work. During the implementation of creative project tasks students acquire the technology of mathematical modeling and abilities and skills of independent work; learn to analyze a situation, choose methods and means of achieving the objective, predict the situation, estimate outcomes, and be responsible for the entire project. Thus, the above approach ensures the development of independent cognitive activity of students alongside with the development of their competences in mathematics.

\section{References}

1. A.S. Sidenko, Assistant Principal 6, 96-111 (2003)

2. N.A. Kralya, Method of educational projects as means of activation of educational activity of pupils: study guide (OSU Publishing house, Omsk, 2005)

3. E.S. Polat, Modern pedagogical and information technologies in education: study guide (M., 2007)

4. I.D. Chechel, Research projects in school practice, Department of research activity of a teacher and a student in modern school (September, M., 1998)

5. L.B. Pereverzev, School and production 1, 14-16 (2002)

6. E.V. Sergeyev, PSU Bulletin 2, 281-285 (2010)
7. E.V. Sergeyev, Mir Nauki: Online magazine, 4 1, (2016)

8. W.H. Kilpatrick, Dewey's Influence on Education, The Philosophy of John Dewey Illinois (1989)

9. K. Nishitani, The History and Present Status of the John Dewey Society (Tokyo, Sept. 12 (1962)

10. A. Stoof, R.L. Marrens, J.G. Merrienboer Jeroen, What is a competence? Constructionist approach as an exit from confusion, Open University of the Netherlands, (2004). Access mode: www.ht.ru. 